Article

\title{
Single-Valued Neutrosophic Hybrid Arithmetic and Geometric Aggregation Operators and Their Decision-Making Method
}

\author{
Zhikang $\mathrm{Lu}$ * and Jun Ye \\ Department of Electrical and Information Engineering, Shaoxing University, 508 Huancheng West Road, \\ Shaoxing 312000, China; yehjun@aliyun.com \\ * Correspondence: luzhikang@usx.edu.cn; Tel.: +86-575-8833-7932
}

Received: 25 June 2017; Accepted: 13 July 2017; Published: 15 July 2017

\begin{abstract}
Single-valued neutrosophic numbers (SVNNs) can express incomplete, indeterminate, and inconsistent information in the real world. Then, the common weighted aggregation operators of SVNNs may result in unreasonably aggregated results in some situations. Based on the hybrid weighted arithmetic and geometric aggregation and hybrid ordered weighted arithmetic and geometric aggregation ideas, this paper proposes SVNN hybrid weighted arithmetic and geometric aggregation (SVNNHWAGA) and SVNN hybrid ordered weighted arithmetic and geometric aggregation (SVNNHOWAGA) operators and investigates their rationality and effectiveness by numerical examples. Then, we establish a multiple-attribute decision-making method based on the SVNNHWAGA or SVNNHOWAGA operator under a SVNN environment. Finally, the multiple-attribute decision-making problem about the design schemes of punching machine is presented as a case to show the application and rationality of the proposed decision-making method.
\end{abstract}

Keywords: multiple-attribute decision-making; single-valued neutrosophic number; single-valued neutrosophic number hybrid weighted arithmetic and geometric aggregation (SVNNHWAGA) operator; single-valued neutrosophic number hybrid ordered weighted arithmetic and geometric aggregation (SVNNHOWAGA) operator

\section{Introduction}

Fuzzy decision-making theory has been an important research topic. Many fuzzy theories, especially like fuzzy (linguistic) sets [1,2], intuitionistic fuzzy sets [3], interval-valued intuitionistic fuzzy sets [4] etc., have been proposed and applied to decision-making problems [5-8]. However, there exists incomplete, indeterminate, and inconsistent information in the real life, which is not expressed by the aforementioned fuzzy sets. To represent incomplete, indeterminate, and inconsistent information, Smarandache [9] firstly proposed neutrosophic sets as the generalization of fuzzy sets, intuitionistic fuzzy sets, and interval-valued intuitionistic fuzzy sets. In the neutrosophic set, its truth, indeterminacy, and falsity membership degrees lie in the real standard/nonstandard interval $\left[{ }^{-} 0,1^{+}\right]$. To constrain them in the real standard interval $[0,1]$ for convenient engineering applications, single-valued neutrosophic sets [10], interval neutrosophic sets [11], and simplified neutrosophic sets (including single-valued neutrosophic sets and interval neutrosophic sets) [12] were introduced as the subclasses of the neutrosophic sets. Recently, many researchers have developed various aggregation operators of simplified neutrosophic numbers (including single-valued/interval neutrosophic numbers) to be used for multiple-attribute decision-making problems with simplified (single-valued/interval) neutrosophic information. For example, they proposed simplified (single-valued/interval) weighted aggregation operators [12], interval neutrosophic number-weighted arithmetic average and interval neutrosophic number-weighted geometric average operators [13], single-valued neutrosophic number normalized 
weighted Bonferroni mean operators [14], generalized neutrosophic number Hamacher aggregation operators [15], interval neutrosophic number generalized weighted aggregation operator [16], interval neutrosophic number Choquet integral operator [17], interval neutrosophic number ordered weighted arithmetic average and interval neutrosophic number ordered weighted geometric average operators [18], interval neutrosophic number prioritized ordered weighted average operator [19], simplified neutrosophic number prioritized aggregation operator [20], single-valued neutrosophic number and interval neutrosophic number exponential weighted aggregation operators [21,22] etc. They have been wildly used for various decision-making problems in engineering, economics, and management areas. Furthermore, some scholars also proposed various multiple-attribute decision-making methods with single-valued neutrosophic numbers and interval neutrosophic numbers [23-27].

In the aforementioned aggregation operators, however, the interval neutrosophic number weighted arithmetic average and interval neutrosophic number weighted geometric average operators and the interval neutrosophic number ordered weighted arithmetic average and interval neutrosophic number ordered weighted geometric average operators are common aggregation operations in information fusion and decision-making areas. Especially when interval membership values in interval neutrosophic numbers are degenerated to any real numbers between 0 and 1 , the interval neutrosophic number weighted arithmetic average (INNWAA) and interval neutrosophic number weighted geometric average (INNWGA) operators [13] can be reduced to the single-valued neutrosophic number weighted arithmetic average (SVNNWAA) and single-valued neutrosophic number weighted geometric average (SVNNWGA) operators, and the interval neutrosophic number ordered weighted arithmetic average (INNOWAA) and interval neutrosophic number ordered weighted geometric average (INNOWGA) operators [18] can be reduced to the single-valued neutrosophic number ordered weighted arithmetic average (SVNNOWAA) and single-valued neutrosophic number ordered weighted geometric average (SVNNOWGA) operators, respectively, as special cases of the existing interval neutrosophic number aggregation operators $[13,18]$. However, they imply the drawbacks of their unreasonably aggregated results in some cases (see Section 2 in detail). For example, in the information aggregations of the SVNNWAA and SVNNOWAA operators, their aggregated results may result in tendency to the maximum value in some cases, while the aggregated results of the SVNNWGA and SVNNOWGA operators may result in tendency to the maximum weight value in some cases. Also, the SVNNWGA and SVNNOWGA operators emphasize personal major points $[13,18]$ and the SVNNWAA and SVNNOWAA operators emphasize group's major points $[13,18]$. Motivated by the hybrid arithmetic and geometric aggregation operators of intuitionistic fuzzy numbers [28], this paper proposes the single-valued neutrosophic number hybrid weighted arithmetic and geometric aggregation (SVNNHWAGA) and single-valued neutrosophic number hybrid ordered weighted arithmetic and geometric aggregation (SVNNHOWAGA) operators to realize more reasonable results in information aggregations of single-valued neutrosophic numbers, and then indicates some properties of the SVNNHWAGA and SVNNHOWAGA operators. Furthermore, a single-valued neutrosophic multiple-attribute decision-making method is established by using the SVNNHWAGA or SVNNHOWAGA operator, and then used for the decision-making problem of design schemes of punching machine under a single-valued neutrosophic environment. The main advantage of this study is that the proposed SVNNHWAGA and SVNNHOWAGA operators can overcome the drawbacks of the existing arithmetic/geometric average aggregation operators of single-valued neutrosophic numbers in some situations and reach the moderate aggregation values.

The remainder of this paper is structured as the following. In Section 2, we introduce some basic concepts and operations of single-valued neutrosophic numbers and investigate some drawbacks of the SVNNWAA, SVNNOWAA, SVNNWGA, and SVNNOWGA operators in some cases. In Section 3, we propose the SVNNHWAGA and SVNNHOWAGA operators and investigate their effectiveness and rationality based on numerical examples. Section 4 develops a single-valued neutrosophic multiple-attribute decision-making method based on the SVNNHWAGA or SVNNHOWAGA operator. 
Section 5 presents a multiple-attribute decision-making problem about the design schemes of punching machine as a case to illustrate the application and effectiveness of the presented decision-making method. Section 6 gives some conclusions and further research.

\section{Some Concepts and Operations of Single-Valued Neutrosophic Numbers}

Definition 1 [1]. Let $X$ be a universal of discourse. A single-valued neutrosophic set $N$ in $X$ is characterized by truth, indeterminacy, and falsity membership functions $T_{N}(x), U_{N}(x)$, and $V_{N}(x)$, respectively, where the values of the three functions $T_{N}(x), U_{N}(x)$, and $V_{N}(x)$ are real numbers between 0 and 1 , satisfying $T_{N}(x), U_{N}(x)$, $V_{N}(x) \in[0,1]$ and $0 \leq T_{N}(x)+U_{N}(x)+V_{N}(x) \leq 3$ for $x \in X$. Thus, the single-valued neutrosophic set $N$ is denoted as the following form:

$$
N=\left\{\left\langle x, T_{N}(x), U_{N}(x), V_{N}(x)\right\rangle \mid x \in X\right\}
$$

For convenience, a basic element $<x, T_{N}(x), U_{N}(x), V_{N}(x)>$ in the single-valued neutrosophic set $N$ is denoted by $z=\langle T, U, V\rangle$ for short, which is called a single-valued neutrosophic number.

Since a single-valued neutrosophic number is a special case of an interval neutrosophic number, the concepts and operations of interval neutrosophic numbers can be introduced to single-valued neutrosophic numbers.

Let two single-valued neutrosophic numbers be $z_{1}=<T_{1}, U_{1}, V_{1}>$ and $z_{2}=<T_{2}, U_{2}, V_{2}>$. Then, there are the following relations [9-13]:

(1) $\left(z_{1}\right)^{\mathrm{c}}=\left\langle V_{1}, 1-U_{1}, T_{1}>\right.$ (complement of $z_{1}$ );

(2) $z_{1} \subseteq z_{2}$ if and only if $T_{1} \leq T_{2}, U_{1} \geq U_{2}$ and $V_{1} \geq V_{2}$;

(3) $z_{1}=z_{2}$ if and only if $z_{1} \subseteq z_{2}$ and $z_{2} \subseteq z_{1}$.

(4) $z_{1} \oplus z_{2}=\left\langle T_{1}+T_{2}-T_{1} T_{2}, U_{1} U_{2}, V_{1} V_{2}\right\rangle$;

(5) $z_{1} \otimes z_{2}=\left\langle T_{1} T_{2}, U_{1}+U_{2}-U_{1} U_{2}, V_{1}+V_{2}-V_{1} V_{2}\right\rangle$;

(6) $\alpha z_{1}=\left\langle 1-\left(1-T_{1}\right)^{\alpha}, U_{1}^{\alpha}, V_{1}^{\alpha}\right\rangle$ for $\alpha>0$;

(7) $z_{1}^{\alpha}=\left\langle z_{1}^{\alpha}, 1-\left(1-U_{1}\right)^{\alpha}, 1-\left(1-V_{1}\right)^{\alpha}\right\rangle$ for $\alpha>0$.

For any single-valued neutrosophic number $z=\langle T, U, V\rangle$, its score and accuracy functions [13] are defined, respectively, as follows:

$$
\begin{gathered}
E(z)=(2+T-U-V) / 3, \quad E(z) \in[0,1] \\
H(z)=T-V, \quad H(z) \in[-1,1]
\end{gathered}
$$

Definition 2 [13]. Let two single-valued neutrosophic numbers be $z_{1}=\left\langle T_{1}, U_{1}, V_{1}>\right.$ and $z_{2}=\left\langle T_{2}, U_{2}, V_{2}\right\rangle$, then the ranking method based on both the score values of $E\left(z_{1}\right)$ and $E\left(z_{2}\right)$ and the accuracy degrees of $H\left(z_{1}\right)$ and $\mathrm{H}\left(\mathrm{z}_{2}\right)$ has the following relations:

(1) If $E\left(z_{1}\right)>E\left(z_{2}\right)$, then $z_{1} \succ z_{2}$;

(2) If $E\left(z_{1}\right)=E\left(z_{2}\right)$ and $H\left(z_{1}\right)>H\left(z_{2}\right)$, then $z_{1} \succ z_{2}$;

(3) If $E\left(z_{1}\right)=E\left(z_{2}\right)$ and $H\left(z_{1}\right)=H\left(z_{2}\right)$, then $z_{1}=z_{2}$.

Let $z_{j}=<T_{j}, U_{j}, V_{j}>(j=1,2, \ldots, n)$ be a collection of single-valued neutrosophic numbers. Then, the SVNNWAA and SVNNWGA operators [13] are introduced, respectively, as follows:

$$
\operatorname{SVNNWAA}\left(z_{1}, z_{2}, \ldots, z_{n}\right)=\sum_{j=1}^{n} w_{j} z_{j}=\left\langle 1-\prod_{j=1}^{n}\left(1-T_{j}\right)^{w_{j}}, \prod_{j=1}^{n}\left(U_{j}\right)^{w_{j}}, \prod_{j=1}^{n}\left(V_{j}\right)^{w_{j}}\right\rangle
$$




$$
\operatorname{SVNNWGA}\left(z_{1}, z_{2}, \ldots, z_{n}\right)=\prod_{j=1}^{n} z_{j}^{w_{j}}=\left\langle\prod_{j=1}^{n}\left(T_{j}\right)^{w_{j}}, 1-\prod_{j=1}^{n}\left(1-U_{j}\right)^{w_{j}}, 1-\prod_{j=1}^{n}\left(1-V_{j}\right)^{w_{j}}\right\rangle
$$

where $w_{j}(j=1,2, \ldots, n)$ is the weight of $z_{j}(j=1,2, \ldots, n)$, satisfying $w_{j} \in[0,1]$ and $\sum_{j=1}^{n} w_{j}=1$.

When the orders of all the arguments are considered by important positions in the aggregation process of single-valued neutrosophic numbers, the SVNNOWAA and SVNNOWGA operators [18] are introduced, respectively, as follows:

$$
\begin{gathered}
\operatorname{SVNNOWAA}\left(z_{1}, z_{2}, \ldots, z_{n}\right)=\sum_{j=1}^{n} \zeta_{j} z_{p(j)}=\left\langle 1-\prod_{j=1}^{n}\left(1-T_{p(j)}\right)^{\zeta_{j}}, \prod_{j=1}^{n}\left(U_{p(j)}\right)^{\zeta_{j}}, \prod_{j=1}^{n}\left(V_{p(j)}\right)^{\zeta_{j}}\right\rangle \\
\operatorname{SVNNOWGA}\left(z_{1}, z_{2}, \ldots, z_{n}\right)=\prod_{j=1}^{n} z_{p(j)}^{\zeta_{j}}=\left\langle\prod_{j=1}^{n}\left(T_{p(j)}\right)^{\zeta_{j}}, 1-\prod_{j=1}^{n}\left(1-U_{p(j)}\right)^{\zeta_{j}}, 1-\prod_{j=1}^{n}\left(1-V_{p(j)}\right)^{\zeta_{j}}\right\rangle
\end{gathered}
$$

where $(p(1), p(2), \ldots, p(n))$ is a permutation of $(1,2, \ldots, n)$ based on $p(j-1) \geq p(j)$ for $j=2, \ldots$, $n ;\left(\zeta_{1}, \zeta_{2}, \ldots, \zeta_{n}\right)$ is an associated weight vector, satisfying $\zeta_{j} \in[0,1]$ and $\sum_{j=1}^{n} \zeta_{j}=1$. Then, the SVNNOWAA and SVNNOWGA operators can reflect the important degrees of the ordered positions of arguments.

Although the above four aggregation operators are common aggregation operations in information fusion and decision-making areas, they imply some drawbacks, which result in tendency to the maximum arguments or weight values of their aggregated values. For example, some drawbacks are shown by the following two numerical examples.

Example 1. Let two single-valued neutrosophic numbers be $z_{1}=\langle 0.001,0,0\rangle$ and $z_{2}=\langle 1,0,0\rangle$ with their weights and associated weights $w_{1}=\zeta_{1}=0.9$ and $w_{2}=\zeta_{2}=0.1$, respectively.

Then, by using Equations (3)-(6) we can yield SVNNWAA $\left(z_{1}, z_{2}\right)=<1,0,0>, \operatorname{SVNNWGA}\left(z_{1}, z_{2}\right)$ $=<0.002,0,0>$, SVNNOWAA $\left(z_{1}, z_{2}\right)=\left\langle 1,0,0>\right.$, and SVNNOWGA $\left(z_{1}, z_{2}\right)=<0.5012,0,0>$.

Example 2. Also take two single-valued neutrosophic numbers $z_{1}=\langle 0.001,0,0\rangle$ and $z_{2}=\langle 1,0,0\rangle$ with their weights $w_{1}=\zeta_{1}=0.1$ and $w_{2}=\zeta_{2}=0.9$, respectively.

Then, we can obtain $\operatorname{SVNNWAA}\left(z_{1}, z_{2}\right)=\langle 1,0,0\rangle, \operatorname{SVNNWGA}\left(z_{1}, z_{2}\right)=\langle 0.5012,0,0\rangle$, $\operatorname{SVNNOWAA}\left(z_{1}, z_{2}\right)=\langle 1,0,0\rangle$, and $\operatorname{SVNNOWGA}\left(z_{1}, z_{2}\right)=\langle 0.002,0,0\rangle$.

From the aggregated results of the two examples, it is obvious that the aggregated values of the SVNNWAA and SVNNOWAA operators indicate tendency to the maximum value, and then the aggregated values of the SVNNWGA and SVNNOWGA operators indicate tendency to the maximum weight value. Therefore, the SVNNWAA, SVNNOWAA, SVNNWGA and SVNNOWGA operators may result in unreasonably aggregated results of single-valued neutrosophic numbers in some cases. To overcome these drawbacks, we need to improve these aggregation operators and to propose hybrid arithmetic and geometric aggregation operators of single-valued neutrosophic numbers as the extension of hybrid arithmetic and geometric aggregation operators of intuitionistic fuzzy numbers in [28].

\section{Hybrid Arithmetic and Geometric Aggregation Operators of Single-Valued Neutrosophic Numbers}

\subsection{SVNNHWAGA Operator}

Definition 3. Let $z_{j}=<T_{j}, U_{j}, V_{j}>(j=1,2, \ldots, n)$ be a collection of single-valued neutrosophic numbers. Then, the SVNNHWAGA operator is defined by 


$$
\operatorname{SVNNHWAGA}\left(z_{1}, z_{2}, \ldots, z_{n}\right)=\left(\sum_{j=1}^{n} w_{j} z_{j}\right)^{\alpha}\left(\prod_{j=1}^{n} z_{j}^{w_{j}}\right)^{(1-\alpha)}
$$

where $w_{j}(j=1,2, \ldots, n)$ is the weight of $z_{j}(j=1,2, \ldots, n)$, satisfying $w_{j} \in[0,1]$ and $\sum_{j=1}^{n} w_{j}=1$, and $\alpha \in[0,1]$.

Theorem 1. Let $z_{j}=\left\langle T_{j}, U_{j}, V_{j}>(j=1,2, \ldots, n)\right.$ be a collection of single-valued neutrosophic numbers and $\alpha$ be any real number in $[0,1]$. Thus, the aggregated value of the SVNNHWAGA operator is also a single-valued neutrosophic number, which is calculated by

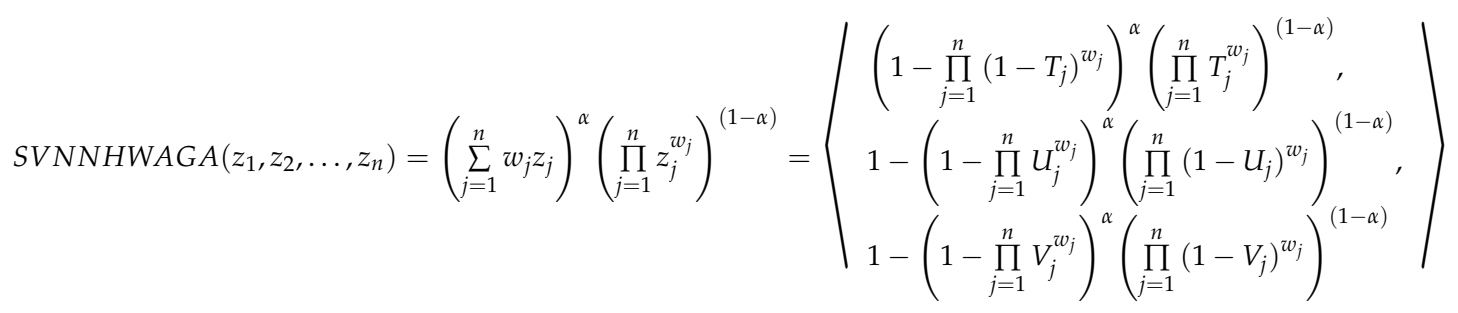

where $w_{j}$ is the weight of $z_{j}(j=1,2, \ldots, n)$, satisfying $w_{j} \in[0,1]$ and $\sum_{j=1}^{n} w_{j}=1$.

Proof. Corresponding to the operational laws of single-valued neutrosophic numbers in Section 2 and the SVNNWAA and SVNNWGA operators, we have the following result:

$$
\begin{aligned}
& \operatorname{SVNNHWAGA}\left(z_{1}, z_{2}, \ldots, z_{n}\right)=\left(\sum_{j=1}^{n} w_{j} z_{j}\right)^{\alpha}\left(\prod_{j=1}^{n} z_{j}^{w_{j}}\right)^{(1-\alpha)} \\
& =\left\langle 1-\prod_{j=1}^{n}\left(1-T_{j}\right)^{w_{j}}, \prod_{j=1}^{n} U_{j}^{w_{j}}, \prod_{j=1}^{n} V_{j}^{w_{j}}\right\rangle^{\alpha}\left\langle\prod_{j=1}^{n} T_{j}^{w_{j}}, 1-\prod_{j=1}^{n}\left(1-U_{j}\right)^{w_{j}}, 1-\prod_{j=1}^{n}\left(1-V_{j}\right)^{w_{j}}\right\rangle^{(1-\alpha)} \\
& =\left\langle\left(1-\prod_{j=1}^{n}\left(1-T_{j}\right)^{w_{j}}\right)^{\alpha}, 1-\left(1-\prod_{j=1}^{n} U_{j}^{w_{j}}\right)^{\alpha}, 1-\left(1-\prod_{j=1}^{n} V_{j}^{w_{j}}\right)^{\alpha}\right\rangle \\
& \times\left\langle\left(\prod_{j=1}^{n} T_{j}^{w_{j}}\right)^{(1-\alpha)}, 1-\left(\prod_{j=1}^{n}\left(1-U_{j}\right)^{w_{j}}\right)^{(1-\alpha)}, 1-\left(\prod_{j=1}^{n}\left(1-V_{j}\right)^{w_{j}}\right)^{(1-\alpha)}\right\rangle \\
& \int\left(1-\prod_{j=1}^{n}\left(1-T_{j}\right)^{w_{j}}\right)^{\alpha}\left(\prod_{j=1}^{n} T_{j}^{w_{j}}\right)^{(1-\alpha)},\left[1-\left(1-\prod_{j=1}^{n} U_{j}^{w_{j}}\right)^{\alpha}+1-\left(\prod_{j=1}^{n}\left(1-U_{j}\right)^{w_{j}}\right)^{(1-\alpha)}\right] \\
& =\left\langle-\left[1-\left(1-\prod_{j=1}^{n} U_{j}^{w_{j}}\right)^{\alpha}\right]\left[1-\left(\prod_{j=1}^{n}\left(1-U_{j}\right)^{w_{j}}\right)^{(1-\alpha)}\right]\right. \text {, } \\
& \left|\left[1-\left(1-\prod_{j=1}^{n} V_{j}^{w_{j}}\right)^{\alpha}+1-\left(\prod_{j=1}^{n}\left(1-V_{j}\right)^{w_{j}}\right)^{(1-\alpha)}\right]-\left[1-\left(1-\prod_{j=1}^{n} V_{j}^{w_{j}}\right)^{\alpha}\right]\left[1-\left(\prod_{j=1}^{n}\left(1-V_{j}\right)^{w_{j}}\right)^{(1-\alpha)}\right]\right| \\
& =\left|\begin{array}{l}
\left(1-\prod_{j=1}^{n}\left(1-T_{j}\right)^{w_{j}}\right)^{\alpha}\left(\prod_{j=1}^{n} T_{j}^{w_{j}}\right)^{(1-\alpha)},\left[1-\left(1-\prod_{j=1}^{n} U_{j}^{w_{j}}\right)^{\alpha}+1-\left(\prod_{j=1}^{n}\left(1-U_{j}\right)^{w_{j}}\right)^{(1-\alpha)}\right] \\
-\left[1-\left(\prod_{j=1}^{n}\left(1-U_{j}\right)^{w_{j}}\right)^{(1-\alpha)}-\left(1-\prod_{j=1}^{n} U_{j}^{w_{j}}\right)^{\alpha}+\left(1-\prod_{j=1}^{n} U_{j}^{w_{j}}\right)^{\alpha}\left(\prod_{j=1}^{n}\left(1-U_{j}\right)^{w_{j}}\right)^{(1-\alpha)}\right] \\
{\left[\begin{array}{l}
\left.1-\left(1-\prod_{j=1}^{n} V_{j}^{w_{j}}\right)^{\alpha}+1-\left(\prod_{j=1}^{n}\left(1-V_{j}\right)^{w_{j}}\right)^{(1-\alpha)}\right] \\
-\left[1-\left(\prod_{j=1}^{n}\left(1-V_{j}\right)^{w_{j}}\right)^{(1-\alpha)}-\left(1-\prod_{j=1}^{n} V_{j}^{w_{j}}\right)^{\alpha}+\left(1-\prod_{j=1}^{n} V_{j}^{w_{j}}\right)^{\alpha}\left(\prod_{j=1}^{n}\left(1-V_{j}\right)^{w_{j}}\right)^{(1-\alpha)}\right]
\end{array}\right.}
\end{array}\right| \\
& =\left|\begin{array}{c}
\left(1-\prod_{j=1}^{n}\left(1-T_{j}\right)^{w_{j}}\right)^{\alpha}\left(\prod_{j=1}^{n} T_{j}^{w_{j}}\right)^{(1-\alpha)}, \\
1-\left(1-\prod_{j=1}^{n} U_{j}^{w_{j}}\right)^{\alpha}\left(\prod_{j=1}^{n}\left(1-U_{j}\right)^{w_{j}}\right)^{(1-\alpha)}, \\
1-\left(1-\prod_{j=1}^{n} V_{j}^{w_{j}}\right)^{\alpha}\left(\prod_{j=1}^{n}\left(1-V_{j}\right)^{w_{j}}\right)^{(1-\alpha)}
\end{array}\right| .
\end{aligned}
$$


Therefore, this completes the proof of Equation (8).

Based on the properties of the INNWAA and INNWGA operators [13], the SVNNHWAGA operator also contains these properties:

(1) Idempotency: If $z_{j}=z$ for $j=1,2, \ldots, n$, then there is $\operatorname{SVNNHWAGA}\left(z_{1}, z_{2}, \cdots, z_{n}\right)=z$.

(2) Boundedness: If $z_{\min }=\min \left(z_{1}, z_{2}, \ldots, z_{n}\right)$ and $z_{\max }=\max \left(z_{1}, z_{2}, \ldots, z_{n}\right)$ for $j=1,2, \ldots, n$, then there exists $z_{\min } \leq \operatorname{SVNNHWAGA}\left(z_{1}, z_{2}, \cdots, z_{n}\right) \leq z_{\max }$.

(3) Monotonicity: If $z_{j} \leq z_{j}^{*}$ for $j=1,2, \ldots, n$, then $\operatorname{SVNNHWAGA}\left(z_{1}, z_{2}, \cdots, z_{n}\right) \leq$ $\operatorname{SVNNHWAGA}\left(z_{1}^{*}, z_{2}^{*}, \cdots, z_{n}^{*}\right)$ holds.

When the some values of $\alpha \in[0,1]$ are specified as the special cases, we can investigate the families of the SVNNHWAGA operator below:

(1) The SVNNHWAGA operator reduces to the SVNNWAA operator if $\alpha=1$;

(2) The SVNNHWAGA operator reduces to the SVNNWGA operator if $\alpha=0$;

(3) The SVNNHWAGA operator is the mean of the SVNNWAA and SVNNWGA operators if $\alpha=0.5$.

\subsection{SVNNHOWAGA Operator}

Definition 4. Let $z_{j}=<T_{j}, U_{j}, V_{j}>(j=1,2, \ldots, n)$ be a collection of single-valued neutrosophic numbers. Then, the SVNNHOWAGA operator is defined by

$$
\operatorname{SVNNHOWAGA}\left(z_{1}, z_{2}, \ldots, z_{n}\right)=\left(\sum_{j=1}^{n} \zeta_{j} z_{p(j)}\right)^{\alpha}\left(\prod_{j=1}^{n} z_{p(j)}^{\zeta_{j}}\right)^{(1-\alpha)}
$$

where $(p(1), p(2), \ldots, p(n))$ is a permutation of $(1,2, \ldots, n)$ based on $p(j-1) \geq p(j)$ for $j=2, \ldots, n ;\left(\zeta_{1}\right.$, $\left.\zeta_{2}, \ldots, \zeta_{n}\right)$ is an associated weight vector, satisfying $\zeta_{j} \in[0,1]$ and $\sum_{j=1}^{n} \zeta_{j}=1 ; \alpha$ is any real number between 0 and 1 . Then, the SVNNHOWAGA operator can reflect the important degrees of the ordered positions of arguments in the aggregated process of single-valued neutrosophic numbers.

Theorem 2. Let $z_{j}=\left\langle T_{j}, U_{j}, V_{j}>(j=1,2, \ldots, n)\right.$ be a collection of single-valued neutrosophic numbers and $\alpha \in[0,1]$. Thus, the aggregated value of the SVNNHOWAGA operator is also a single-valued neutrosophic number, which is calculated by

$$
\operatorname{SVNNHOWAGA}\left(z_{1}, z_{2}, \ldots, z_{n}\right)=\left(\sum_{j=1}^{n} \zeta_{j} z_{p(j)}\right)^{\alpha}\left(\prod_{j=1}^{n} z_{p(j)}^{\zeta_{j}}\right)^{(1-\alpha)}=\left|\begin{array}{c}
\left(1-\prod_{j=1}^{n}\left(1-T_{p(j)}\right)^{\zeta_{j}}\right)^{\alpha}\left(\prod_{j=1}^{n} T_{p(j)}^{\zeta_{j}}\right)^{(1-\alpha)}, \\
1-\left(1-\prod_{j=1}^{n} U_{p(j)}^{\zeta_{j}}\right)^{\alpha}\left(\prod_{j=1}^{n}\left(1-U_{p(j)}\right)^{\zeta_{j}}\right)^{(1-\alpha)}, \\
1-\left(1-\prod_{j=1}^{n} V_{p(j)}^{\zeta_{j}}\right)^{\alpha}\left(\prod_{j=1}^{n}\left(1-V_{p(j)}\right)^{\zeta_{j}}\right)^{(1-\alpha)}
\end{array}\right|
$$

where $(p(1), p(2), \ldots, p(n))$ is a permutation of $(1,2, \ldots, n)$ based on $p(j-1) \geq p(j)$ for $j=2, \ldots, n ;\left(\zeta_{1}\right.$, $\left.\zeta_{2}, \ldots, \zeta_{n}\right)$ is an associated weight vector with $\sum_{j=1}^{n} \zeta_{j}=1$ for $\zeta_{j} \in[0,1]$.

Based on the similar proof manner of Theorem 1, it is obvious that Equation (10) can hold. Here, we omit the proof.

Corresponding to the properties of the INNOWAA and INNOWGA operators in [18], the SVNNHOWAGA operator also contains the following properties:

(1) Idempotency: If $z_{j}=z$ for $j=1,2, \ldots, n$, then there exists $\operatorname{SVNNHOWAGA}\left(z_{1}, z_{2}, \ldots, z_{n}\right)=z$.

(2) Boundedness: If $z_{\min }=\min \left(z_{1}, z_{2}, \ldots, z_{n}\right)$ and $z_{\max }=\max \left(z_{1}, z_{2}, \ldots, z_{n}\right)$ for $j=1,2, \ldots, n$, then there exists $z_{\min } \leq \operatorname{SVNNHOWAGA}\left(z_{1}, z_{2}, \cdots, z_{n}\right) \leq z_{\max }$. 
(3) Monotonicity: If $z_{j} \leq z_{j}^{*}$ for $j=1,2, \ldots, n$, then $\operatorname{SVNNHOWAGA}\left(z_{1}, z_{2}, \cdots, z_{n}\right) \leq$ SVNNHOWAGA $\left(z_{1}^{*}, z_{2}^{*}, \cdots, z_{n}^{*}\right)$ holds.

(4) Commutativity: If $\left(z_{1}^{\prime}, z_{2}^{\prime}, \cdots, z_{n}^{\prime}\right)$ is any permutation of $\left(z_{1}, z_{2}, \cdots, z_{n}\right)$, then $\operatorname{SVNNHOWAGA}\left(z_{1}, z_{2}, \cdots, z_{n}\right)=\operatorname{SVNNHOWAGA}\left(z_{1}^{\prime}, z_{2}^{\prime}, \cdots, z_{n}^{\prime}\right)$ holds.

When some values of $\alpha \in[0,1]$ are specified as the special cases, we can investigate the families of the SVNNHOWAGA operator below:

(1) The SVNNHOWAGA operator reduces to the SVNNOWAA operator if $\alpha=1$;

(2) The SVNNHOWAGA operator reduces to the SVNNOWGA operator if $\alpha=0$;

(3) The SVNNHOWAGA operator is the mean of the SVNNOWAA and SVNNOWGA operators if $\alpha=0.5$.

\subsection{Numerical Examples}

We still consider the aforementioned two numerical examples to illustrate the effectiveness and rationality of the aggregated values of the SVNNHWAGA and SVNNHOWAGA operators. Generally taking $\alpha=0.5$, we apply the SVNNHWAGA and SVNNHOWAGA operators to calculate the two numerical examples in Section 2.

For Example 1, by using Equations (8) and (10) we can obtain $\operatorname{SVNNHWAGA}\left(z_{1}, z_{2}\right)=<0.0447$, $0,0>$, which is the moderate value between $\operatorname{SVNNWAA}\left(z_{1}, z_{2}\right)=<1,0,0>$ and $\operatorname{SVNNWGA}\left(z_{1}, z_{2}\right)$ $=\langle 0.002,0,0\rangle$, and SVNNHOWAGA $\left(z_{1}, z_{2}\right)=\langle 0.7079,0,0\rangle$, which is the moderate value between $\operatorname{SVNNOWAA}\left(z_{1}, z_{2}\right)=<1,0,0>$ and $\operatorname{SVNNOWGA}\left(z_{1}, z_{2}\right)=\langle 0.5012,0,0\rangle$.

For Example 2, by using Equations (8) and (10) we get $\operatorname{SVNNHWAGA}\left(z_{1}, z_{2}\right)=<0.7079,0$, $0>$, which is the moderate value between $\operatorname{SVNNWAA}\left(z_{1}, z_{2}\right)=<1,0,0>$ and $\operatorname{SVNNWGA}\left(z_{1}, z_{2}\right)=$ $<0.5012,0,0>$, and SVNNHOWAGA $\left(z_{1}, z_{2}\right)=\langle 0.0447,0,0\rangle$, which is the moderate value between $\operatorname{SVNNOWAA}\left(z_{1}, z_{2}\right)=\left\langle 1,0,0>\right.$ and $\operatorname{SVNNOWGA}\left(z_{1}, z_{2}\right)=\langle 0.002,0,0>$.

From the above aggregated results of the two numerical examples, the SVNNHWAGA and SVNNHOWAGA operators indicate their moderate values. Obviously, the SVNNHWAGA and SVNNHOWAGA operators demonstrate their effectiveness and rationality in the information aggregations.

\section{Decision-Making Method Using the SVNNHWAGA or SVNNHOWAGA Operator}

This section develops a multiple-attribute decision-making method by using the SVNNHWAGA or SVNNHOWAGA operator.

In a multiple-attribute decision-making problem, suppose that $Z=\left\{Z_{1}, Z_{2}, \ldots, Z_{m}\right\}$ is a set of alternatives and $A=\left\{A_{1}, A_{2}, \ldots, A_{n}\right\}$ is a set of attributes. By decision-makers' suitability evaluation for each attribute $A_{j}$ over each alternative $Z_{i}$, all the evaluation values are expressed by single-valued neutrosophic numbers $z_{i j}=\left\langle T_{i j}, U_{i j}, V_{i j}>\right.$, where $T_{i j}, U_{i j}, V_{i j} \in[0,1]$ and $0 \leq T_{i j}+U_{i j}+V_{i j} \leq 3(j=1$, $2, \ldots, n ; i=1,2, \ldots, m)$. In the single-valued neutrosophic number $z_{i j}, T_{i j}$ indicates the degree that the alternative $Z_{i}$ is suitable for the attribute $A_{j}, U_{i j}$ indicates the degree that the alternative $Z_{i}$ is unsure/indeterminate for the attribute $A_{j}$, and $V_{i j}$ indicates the degree that the alternative $Z_{i}$ is unsuitable for the attribute $A_{j}$. Thus, all the evaluation values can be constructed as a single-valued neutrosophic decision matrix $D=\left(z_{i j}\right)_{m \times n}$.

Hence, we can apply the proposed decision-making method based on the SVNNHWAGA or SVNNHOWAGA operator to the multiple-attribute decision-making problem and give the following decision procedures: 
Step 1. Suppose that the weight vector of attributes is $w=\left(w_{1}, w_{2}, \ldots, w_{n}\right)$ and satisfies $\sum_{j=1}^{n} w_{j}=1$ for $w_{j} \in[0,1]$. Then, the aggregated value of $z_{i}(i=1,2, \ldots, m)$ for each alternative $Z_{i}(i=1,2$, $\ldots, m)$ is calculated by the following SVNNHWAGA operator:

$$
z_{i}=\operatorname{SVNNHWAGA}\left(z_{i 1}, z_{i 2}, \ldots, z_{i n}\right)=\left(\sum_{j=1}^{n} w_{j} z_{i j}\right)^{\alpha}\left(\prod_{j=1}^{n} z_{i j}^{w_{j}}\right)^{(1-\alpha)}=\left\{\begin{array}{c}
\left(1-\prod_{j=1}^{n}\left(1-T_{i j}\right)^{w_{j}}\right)^{\alpha}\left(\prod_{j=1}^{n} T_{i j}^{w_{j}}\right)^{(1-\alpha)}, \\
1-\left(1-\prod_{j=1}^{n} U_{i j}^{w_{j}}\right)^{\alpha}\left(\prod_{j=1}^{n}\left(1-U_{i j}\right)^{w_{j}}\right)^{(1-\alpha)}, \\
1-\left(1-\prod_{j=1}^{n} V_{i j}^{w_{j}}\right)^{\alpha}\left(\prod_{j=1}^{n}\left(1-V_{i j}\right)^{w_{j}}\right)^{(1-\alpha)}
\end{array} \mid\right.
$$

On the other hand, suppose that the ordered important positions of all the arguments are given by the associated weight vector $\zeta=\left(\zeta_{1}, \zeta_{2}, \ldots, \zeta_{n}\right)$, satisfying $\sum_{j=1}^{n} \zeta_{j}=1$ for $\zeta_{j} \in[0,1]$. Thus, the aggregated value of $z_{i}(i=1,2, \ldots, m)$ for each alternative $Z_{i}(i=1,2, \ldots, m)$ is calculated by the following SVNNHOWAGA operator:

$$
z_{i}=\operatorname{SVNNHOWAGA}\left(z_{i 1}, z_{i 2}, \ldots, z_{i n}\right)=\left(\sum_{j=1}^{n} \zeta_{j} z_{i p(j)}\right)^{\alpha}\left(\prod_{j=1}^{n} z_{i p(j)}^{\zeta_{j}}\right)^{(1-\alpha)}=\left|\begin{array}{c}
\left(1-\prod_{j=1}^{n}\left(1-T_{i p(j)}\right)^{\zeta_{j}}\right)^{\alpha}\left(\prod_{j=1}^{n} T_{i p(j)}^{\zeta_{j}}\right)^{(1-\alpha)}, \\
1-\left(1-\prod_{j=1}^{n} u_{i p(j)}^{\zeta_{j}}\right)^{\alpha}\left(\prod_{j=1}^{n}\left(1-U_{i p(j)}\right)^{\zeta_{j}}\right)^{(1-\alpha)} \\
1-\left(1-\prod_{j=1}^{n} V_{i p(j)}^{\zeta_{j}}\right)^{\alpha}\left(\prod_{j=1}^{n}\left(1-V_{i p(j)}\right)^{\zeta_{j}}\right)^{(1-\alpha)}
\end{array}\right|
$$

Step 2. By Equation (1) (Equation (2) if necessary), we calculate the score values of $E\left(z_{i}\right)$ (accuracy degrees of $H\left(z_{i}\right)$ if necessary) $(i=1,2, \ldots, m)$.

Step 3. Corresponding to the score values (accuracy degrees), we rank all the alternatives in a descending order and determine the best choice based on the alternative with the largest value.

Step 4. End.

\section{MADM Problem of the Design Schemes of Punching Machine}

In this section, an applied example about the multiple-attribute decision-making (MADM) problem of the design schemes (alternatives) of punching machine is introduced from [29] to illustrate the application and rationality of the proposed decision-making method by the actual case.

The conceptual design stage mainly contains two tasks, in which designers firstly provide different design schemes (potential alternatives) according to their knowledge and experience, and then decision makers (designers) give their suitability evaluation (decision making) of all the potential design schemes.

Some manufacturing company wants to design the punching machine to develop a new mechanical product. Generally speaking, the punching machine consists of the reducing mechanism, punching mechanism, and feed intermittent mechanism to construct its motion scheme. Based on the motion scheme, a group of designers provides a set of four potential design schemes (alternatives) $Z=\left\{Z_{1}, Z_{2}, Z_{3}, Z_{4}\right\}$ by their knowledge and experiences, which are shown in Table 1 . The designers (decision makers) must make a decision depending on the requirements of the four attributes: (a) $A_{1}$ is the manufacturing cost; (b) $A_{2}$ is the structure complexity; (c) $A_{3}$ is the transmission effectiveness; (d) $A_{4}$ is the reliability; (e) $A_{5}$ is the maintainability. By the decision makers' suitability evaluation for the alternatives of $Z_{i}(i=1,2,3,4)$ with respect to the attributes of $A_{j}(j=1,2,3,4,5)$, their evaluation 
values are expressed by the form of single-valued neutrosophic numbers. Thus, the single-valued neutrosophic number decision matrix $D=\left(z_{i j}\right)_{4 \times 5}$ can be constructed as follows:

$$
D=\left[\begin{array}{ccccc}
(0.75,0.1,0.4) & (0.8,0.1,0.3) & (0.85,0.1,0.2) & (0.85,0.1,0.3) & (0.9,0.1,0.2) \\
(0.7,0.1,0.5) & (0.75,0.1,0.1) & (0.75,0.2,0.1) & (0.8,0.1,0.1) & (0.8,0.2,0.3) \\
(0.8,0.2,0.3) & (0.78,0.1,0.2) & (0.8,0.1,0.2) & (0.8,0.2,0.2) & (0.75,0.1,0.3) \\
(0.9,0.1,0.2) & (0.85,0.1,0.1) & (0.9,0.1,0.2) & (0.85,0.1,0.3) & (0.85,0.2,0.3)
\end{array}\right]
$$

Table 1. Four design schemes (potential alternatives) of punching machine [29].

\begin{tabular}{ccccc}
\hline Potential Alternative & $Z_{1}$ & $Z_{2}$ & $Z_{3}$ & $Z_{4}$ \\
\hline Reducing mechanism & Gear reducer & Gear head motor & Gear reducer & Gear head motor \\
\hline $\begin{array}{c}\text { Punching mechanism } \\
\text { Dial feed intermittent mechanism }\end{array}$ & $\begin{array}{c}\text { Crank-slider mechanism } \\
\text { Sheave }\end{array}$ & $\begin{array}{c}\text { Six-bar punching mechanism } \\
\text { mechanism }\end{array}$ & $\begin{array}{c}\text { Six-bar punching mechanism } \\
\text { Ratchet feed mechank-slider mechanism }\end{array}$ \\
\hline
\end{tabular}

Then, we can apply the developed decision-making method based on the SVNNHWAGA or SVNNHOWAGA operator to the multiple-attribute decision-making problem of the design schemes of punching machine.

If the weight vector of the five attributes is considered as $w=(0.25,0.2,0.25,0.15,0.15)$ in the multiple-attribute decision-making problem, then the decision steps are presented as follows:

Step 1. By Equation (11) (generally take $\alpha=0.5)$, we calculate the aggregated values of $z_{i}(i=1,2,3,4)$ for each alternative $Z_{i}(i=1,2,3,4)$ as the following results:

$z_{1}=\left\langle 0.8255,0.1000,0.2818>, z_{2}=\langle 0.7534,0.1367,0.2149\rangle, z_{3}=\langle 0.7888,0.1367,0.2384>\right.$, and $z_{4}=<0.8761,0.1134,0.2049>$.

Step 2. By Equation (1), we calculate the score values of $E\left(z_{i}\right)$ for each alternative $Z_{i}(i=1,2,3,4)$ as the following values:

$E\left(z_{1}\right)=0.8145, E\left(z_{2}\right)=0.8006, E\left(z_{3}\right)=0.8045$, and $E\left(z_{4}\right)=0.8526$.

Step 3. According to $E\left(z_{4}\right)>E\left(z_{1}\right)>E\left(z_{3}\right)>E\left(z_{2}\right)$, the ranking of the four design schemes is $Z_{4} \succ Z_{1} \succ$ $Z_{3} \succ Z_{2}$. So, the best design scheme is $Z_{4}$. These results are the same as in [29].

If the associated weight vector $\zeta=(0.4,0.3,0.1,0.1,0.1)$ is considered as the ordered important positions of all the given arguments in the multiple-attribute decision-making problem, the decision steps are described as the follows:

Step 1'. By Equation (12) (in general take $\alpha=0.5)$, we calculate the aggregated values of $z_{i}(i=1,2,3$, 4) for each alternative $Z_{i}(i=1,2,3,4)$ as the following results:

$z_{1}=\left\langle 0.8577,0.1000,0.2378>, z_{2}=\left\langle 0.7708,0.1179,0.1520>, z_{3}=\langle 0.7892,0.1179,0.2190>\right.\right.$, and $z_{4}=<0.8711,0.1089,0.1740>$.

Step 2'. By Equation (1), we calculate the score values of $E\left(z_{i}\right)$ for each scheme $Z_{i}(i=1,2,3,4)$ as the following values:

$E\left(z_{1}\right)=0.8400, E\left(z_{2}\right)=0.8336, E\left(z_{3}\right)=0.8174$, and $E\left(z_{4}\right)=0.8627$.

Step $3^{\prime}$. According to $E\left(z_{4}\right)>E\left(z_{1}\right)>E\left(z_{2}\right)>E\left(z_{3}\right)$, the ranking of the four design schemes is $Z_{4} \succ Z_{1} \succ$ $Z_{2} \succ Z_{3}$. Thus, the best design scheme is also $Z_{4}$.

Although the above two ranking orders show little difference, the best scheme $Z_{4}$ is identical.

For comparative convenience, all the results of the proposed decision-making approach and the related decision-making methods based on the SVNNWAA, SVNNWGA, SVNNOWAA, and SVNNOWGA operators are summarized in Table 2. 
Table 2. Decision-making results of different aggregation operators.

\begin{tabular}{|c|c|c|c|}
\hline Aggregation Operator & Aggregated Result & Score Value & Ranking \\
\hline $\begin{array}{l}\text { SVNNWAA } \\
\qquad(\alpha=1)\end{array}$ & $\begin{array}{l}z_{1}=<0.8301,0.1000,0.2741> \\
z_{2}=<0.7553,0.1320,0.1763> \\
z_{3}=<0.7892,0.1320,0.2352> \\
z_{4}=<0.8775,0.1110,0.1966>\end{array}$ & $\begin{array}{l}E\left(z_{1}\right)=0.8187 \\
E\left(z_{2}\right)=0.8157 \\
E\left(z_{3}\right)=0.8073 \\
E\left(z_{4}\right)=0.8566\end{array}$ & $Z_{4} \succ Z_{1} \succ Z_{2} \succ Z_{3}$ \\
\hline $\begin{array}{l}\text { SVNNWGA } \\
\quad(\alpha=0)\end{array}$ & $\begin{array}{l}z_{1}=\langle 0.8209,0.1000,0.2895> \\
z_{2}=<0.7516,0.1414,0.2517> \\
z_{3}=\langle 0.7883,0.1414,0.2416> \\
z_{4}=<0.8746,0.1158,0.2131>\end{array}$ & $\begin{array}{l}E\left(z_{1}\right)=0.8105 \\
E\left(z_{2}\right)=0.7861 \\
E\left(z_{3}\right)=0.8018 \\
E\left(z_{4}\right)=0.8486\end{array}$ & $Z_{4} \succ Z_{1} \succ Z_{3} \succ Z_{2}$ \\
\hline $\begin{array}{l}\text { SVNNHWAGA } \\
\qquad(\alpha=0.5)\end{array}$ & $\begin{array}{l}z_{1}=<0.8255,0.1000,0.2818> \\
z_{2}=<0.7534,0.1367,0.2149> \\
z_{3}=<0.7888,0.1367,0.2384> \\
z_{4}=<0.8761,0.1134,0.2049>\end{array}$ & $\begin{array}{l}E\left(z_{1}\right)=0.8145 \\
E\left(z_{2}\right)=0.8006 \\
E\left(z_{3}\right)=0.8045 \\
E\left(z_{4}\right)=0.8526\end{array}$ & $Z_{4} \succ Z_{1} \succ Z_{3} \succ Z_{2}$ \\
\hline $\begin{array}{l}\text { SVNNOWAA } \\
\qquad(\alpha=1)\end{array}$ & $\begin{array}{l}z_{1}=\langle 0.8619,0.1000,0.2325\rangle \\
z_{2}=<0.7723,0.1149,0.1311> \\
z_{3}=<0.7896,0.1149,0.2169> \\
z_{4}=<0.8725,0.1072,0.1644>\end{array}$ & $\begin{array}{l}E\left(z_{1}\right)=0.8431 \\
E\left(z_{2}\right)=0.8421 \\
E\left(z_{3}\right)=0.8193 \\
E\left(z_{4}\right)=0.8670\end{array}$ & $Z_{4} \succ Z_{1} \succ Z_{2} \succ Z_{3}$ \\
\hline $\begin{array}{l}\text { SVNNOWGA } \\
\qquad(\alpha=0)\end{array}$ & $\begin{array}{l}z_{1}=\langle 0.8536,0.1000,0.2432> \\
z_{2}=<0.7693,0.1210,0.1724> \\
z_{3}=<0.7888,0.1210,0.2211> \\
z_{4}=<0.8697,0.1105,0.1835>\end{array}$ & $\begin{array}{l}E\left(z_{1}\right)=0.8368 \\
E\left(z_{2}\right)=0.8253 \\
E\left(z_{3}\right)=0.8156 \\
E\left(z_{4}\right)=0.8585\end{array}$ & $Z_{4} \succ Z_{1} \succ Z_{2} \succ Z_{3}$ \\
\hline $\begin{array}{l}\text { SVNNHOWAGA } \\
\qquad(\alpha=0.5)\end{array}$ & $\begin{array}{l}z_{1}=\langle 0.8577,0.1000,0.2378> \\
\left.z_{2}=<0.7708,0.1179,0.1520\right\rangle \\
z_{3}=<0.7892,0.1179,0.2190> \\
\left.z_{4}=<0.8711,0.1089,0.1740\right\rangle\end{array}$ & $\begin{array}{l}E\left(z_{1}\right)=0.8400 \\
E\left(z_{2}\right)=0.8336 \\
E\left(z_{3}\right)=0.8174 \\
E\left(z_{4}\right)=0.8627\end{array}$ & $Z_{4} \succ Z_{1} \succ Z_{2} \succ Z_{3}$ \\
\hline
\end{tabular}

The results of Table 2 show that all the aggregated results of the SVNNHWAGA and SVNNHOWAGA operators tend toward moderate values between the aggregated values of the SVNNWAA and SVNNWGA operators or the SVNNOWAA and SVNNOWGA operators. Hence, the SVNNHWAGA and SVNNHOWAGA operators are suitable and effective and can overcome the drawbacks of the SVNNWAA, SVNNOWAA, SVNNWGA and SVNNOWGA operators. Furthermore, the different aggregation operators may show different ranking orders. Then, the different values of $\alpha$ may result in different ranking orders.

Compared with the decision-making method based on the hybrid arithmetic and geometric aggregation operators of intuitionistic fuzzy numbers introduced by Ye [28], Ye's method [28] uses the hybrid arithmetic and geometric aggregation operators of intuitionistic fuzzy numbers to aggregate intuitionistic fuzzy numbers and applied them to multiple-attribute decision-making problems under an intuitionistic fuzzy number environment; while the multiple-attribute decision-making method proposed in this paper uses the hybrid arithmetic and geometric aggregation operators of single-valued neutrosophic numbers to aggregate single-valued neutrosophic information as the extension of the hybrid arithmetic and geometric aggregation operators of intuitionistic fuzzy numbers and extends the decision-making method based on the hybrid arithmetic and geometric aggregation operators of intuitionistic fuzzy numbers [28], because an intuitionistic fuzzy number is a special case of a single-valued neutrosophic number and cannot express and handle indeterminate and inconsistent information. Thus, it is obvious that the SVNNHWAGA and SVNNHOWAGA operators and their decision-making method proposed in this paper are superior to the previous hybrid arithmetic and geometric aggregation operators and decision-making method with intuitionistic fuzzy numbers [28], because the latter cannot express and deal with the decision-making problems with indeterminate and inconsistent information. Hence, the proposed SVNNHWAGA and SVNNHOWAGA operators and their decision-making method in this study are more general and more suitable under indeterminate and inconsistent environments than the previous Ye's method [28]. 
However, the presented decision-making method based on the SVNNHWAGA or SVNNHOWAGA operator demonstrates its suitability and effectiveness in some decision-making situations since it can overcome the drawbacks of the unreasonably aggregated results in some cases (as mentioned in Section 2). Since some value of $\alpha$ is specified by the preference and actual requirements of decision makers, the decision-making method proposed in this study appears to be more flexible and more reasonable than the decision-making method based on one of the SVNNWAA, SVNNOWAA, SVNNWGA, and SVNNOWGA operators.

\section{Conclusions}

This paper presented the SVNNHWAGA and SVNNHOWAGA operators to overcome some drawbacks of the SVNNWAA, SVNNOWAA, SVNNWGA and SVNNOWGA operators to aggregate single-valued neutrosophic numbers in some cases, and then investigated their some properties and rationality. Furthermore, we established a multiple-attribute decision-making method based on the SVNNHWAGA or SVNNHOWAGA operator. Finally, a multiple-attribute decision-making problem about design schemes of punching machine is presented as a case to show the application and rationality of the proposed decision-making method. However, the proposed decision-making method based on the SVNNHWAGA or SVNNHOWAGA operator provides an effective and reasonable way for multiple-attribute decision-making problems since the SVNNWAA, SVNNOWAA, SVNNWGA and SVNNOWGA operators are special cases of the SVNNHWAGA and SVNNHOWAGA operators under a single-valued neutrosophic environment. Similarly, this study will be also further extended to interval neutrosophic sets and applications, like group decision making, pattern recognition, fault diagnosis, and medical diagnosis, and so on.

Acknowledgments: This paper was supported by the National Natural Science Foundation of China (No. 71471172).

Author Contributions: Zhikang Lu proposed the SVNNHWAGA and SVNNHOWAGA operators and their decision-making method; Jun Ye presented a multiple-attribute decision-making problem about design schemes of punching machine and gave comparative analysis; both authors wrote the paper together.

Conflicts of Interest: The authors declare no conflict of interest.

\section{References}

1. Zadeh, L.A. Fuzzy Sets. Inf. Control 1965, 8, 338-353. [CrossRef]

2. Zadeh, L.A. The concept of a linguistic variable and its application to approximate reasoning Part I. Inf. Sci. 1975, 8, 199-249. [CrossRef]

3. Atanassov, K. Intuitionistic fuzzy sets. Fuzzy Sets Syst. 1986, 20, 87-96. [CrossRef]

4. Atanassov, K.; Gargov, G. Interval-valued intuitionistic fuzzy sets. Fuzzy Sets Syst. 1989, 31, $343-349$. [CrossRef]

5. Ye, J. Multicriteria decision-making method using the Dice similarity measure based on the reduct intuitionistic fuzzy sets of interval-valued intuitionistic fuzzy sets. Appl. Math. Model. 2012, 36, 4466-4472. [CrossRef]

6. De Maio, C.; Fenza, G.; Loia, V.; Orciuoli, F.; Herrera-Viedma, E. A context-aware fuzzy linguistic consensus model supporting innovation processes. In Proceedings of the 2016 IEEE International Conference on Fuzzy Systems, Vancouver, BC, Canada, 24-29 July 2016; pp. 1685-1692.

7. De Maio, C.; Fenza, G.; Loia, V.; Orciuoli, F.; Herrera-Viedma, E. A framework for context-aware heterogeneous group decision making in business processes. Knowl.-Based Syst. 2016, 102, 39-50. [CrossRef]

8. Wan, S.P.; Xu, J.; Dong, J.Y. Aggregating decision information into interval-valued intuitionistic fuzzy numbers for heterogeneous multi-attribute group decision making. Knowl.-Based Syst. 2016, 113, 155-170. [CrossRef]

9. Smarandache, F. Neutrosophy: Neutrosophic Probability, Set, and Logic; American Research Press: Rehoboth, DE, USA, 1998. 
10. Wang, H.; Smarandache, F.; Zhang, Y.Q.; Sunderraman, R. Single valued neutrosophic sets. Multisp. Multistruct. 2010, 4, 410-413.

11. Wang, H.; Smarandache, F.; Zhang, Y.Q.; Sunderraman, R. Interval Neutrosophic Sets and Logic: Theory and Applications in Computing; Hexis: Phoenix, AZ, USA, 2005.

12. Ye, J. A multicriteria decision-making method using aggregation operators for simplified neutrosophic sets. J. Intell. Fuzzy Syst. 2014, 26, 2459-2466.

13. Zhang, H.Y.; Wang, J.Q.; Chen, X.H. Interval neutrosophic sets and their application in multicriteria decision making problems. Sci. World J. 2014, 2014, 645953. [CrossRef] [PubMed]

14. Liu, P.D.; Wang, Y.M. Multiple attribute decision making method based on single-valued neutrosophic normalized weighted Bonferroni mean. Neural Comput. Appl. 2014, 25, 2001-2010. [CrossRef]

15. Liu, P.D.; Chu, Y.C.; Li, Y.W.; Chen, Y.B. Some generalized neutrosophic number Hamacher aggregation operators and their application to group decision making. J. Int. Fuzzy Syst. 2014, 16, 242-255.

16. Zhao, A.W.; Du, J.G.; Guan, H.J. Interval valued neutrosophic sets and multi-attribute decision-making based on generalized weighted aggregation operator. J. Intell. Fuzzy Syst. 2015, 29, 2697-2706.

17. Sun, H.X.; Yang, H.X.; Wu, J.Z.; Yao, O.Y. Interval neutrosophic numbers Choquet integral operator for multi-criteria decision making. J. Intell. Fuzzy Syst. 2015, 28, 2443-2455. [CrossRef]

18. Ye, J. Multiple attribute decision-making method based on the possibility degree ranking method and ordered weighted aggregation operators of interval neutrosophic numbers. J. Intell. Fuzzy Syst. 2015, 28, 1307-1317.

19. Liu, P.D.; Wang, Y.M. Interval neutrosophic prioritized OWA operator and its application to multiple attribute decision making. J. Syst. Sci. Complex. 2016, 29, 681-697. [CrossRef]

20. Wu, X.H.; Wang, J.Q.; Peng, J.J.; Chen, X.H. Cross-entropy and prioritized aggregation operator with simplified neutrosophic sets and their application in multi-criteria decision-making problems. Int. J. Fuzzy Syst. 2016, 18, 1104-1116. [CrossRef]

21. Ye, J. Exponential operations and aggregation operators of interval neutrosophic sets and their decision making methods. SpringerPlus 2016, 5, 1488. [CrossRef] [PubMed]

22. Lu, Z.K.; Ye, J. Exponential operations and aggregation method of single-valued neutrosophic numbers for decision making. Information 2017, 8, 62. [CrossRef]

23. Bausys, R.; Zavadskas, K.E.; Kaklauskas, A. Application of neutrosophic set to multicriteria decision making by COPRAS. J. Econ. Comput. Econ. Cybernet. Stud. Res. 2015, 49, 91-106.

24. Zavadskas, E.K.; Bausys, R.; Lazauskas, M. Sustainable assessment of alternative sites for the construction of a waste incineration plant by applying WASPAS method with single-valued neutrosophic set. Sustainability 2015, 7, 15923-15936. [CrossRef]

25. Tian, Z.P.; Zhang, H.Y.; Wang, J.; Wang, J.Q.; Chen, X.H. Multi-criteria decision-making method based on a cross-entropy with interval neutrosophic sets. Int. J. Syst. Sci. 2016, 47, 3598-3608. [CrossRef]

26. Pouresmaeil, H.; Shivanian, E.; Khorram, E.; Fathabadi, H.S. An extended method using TOPSIS and VIKOR for multiple attribute decision making with multiple decision makers and single valued neutrosophic numbers. Adv. Appl. Stat. 2017, 50, 261-292. [CrossRef]

27. Chen, J.Q.; Ye, J. Some single-valued neutrosophic Dombi weighted aggregation operators for multiple attribute decision-making. Symmetry 2017, 9, 82. [CrossRef]

28. Ye, J. Intuitionistic fuzzy hybrid arithmetic and geometric aggregation operators for the decision-making of mechanical design schemes. Appl. Intell. 2017. [CrossRef]

29. Ye, J. Projection and bidirectional projection measures of single valued neutrosophic sets and their decision-making method for mechanical design schemes. J. Exp. Theor. Artif. Intell. 2016. [CrossRef]

(C) 2017 by the authors. Licensee MDPI, Basel, Switzerland. This article is an open access article distributed under the terms and conditions of the Creative Commons Attribution (CC BY) license (http:/ / creativecommons.org/licenses/by/4.0/). 